\title{
Evolution of Salt Tolerance in Arabidopsis Thaliana on Siliceous Soils Does Not Convey Tolerance to Saline Calcareous Soils
}

\section{Laura Pérez-Martín}

Universitat Autònoma de Barcelona

\section{Silvia Busoms}

Universitat Autònoma de Barcelona https://orcid.org/0000-0002-9917-7118

\section{Maria Jose Almira}

Universitat Autònoma de Barcelona

Nicole Azagury

Universitat Autònoma de Barcelona

Joana Terés

Universitat Autònoma de Barcelona

\section{Roser Tolrà}

Universitat Autònoma de Barcelona

Charlotte Poschenrieder

Universitat Autònoma de Barcelona

Juan Barcelo ( $\sim$ Juan.Barcelo@uab.es )

Universidad Autonoma de Barcelona https://orcid.org/0000-0003-3068-2738

\section{Research Article}

Keywords: Saline-alkaline soils, Arabidopsis thaliana, plasticity, local adaptation, NINJA, CCB4

Posted Date: December 20th, 2021

DOI: https://doi.org/10.21203/rs.3.rs-1173223/v1

License: (c) (i) This work is licensed under a Creative Commons Attribution 4.0 International License. Read Full License 


\section{Abstract}

Purpose Alkaline salinity constrains crop yield. Previously, we found local adaptation of Arabidopsis thaliana demes to saline-siliceous soils $(\mathrm{pH} \leq 7)$ and to non-saline carbonate soils. However, any natural population of $A$. thaliana was localized on saline-alkaline soils. This suggests that salinity tolerance evolved on saline-siliceous soils may not confer tolerance to alkaline salinity. This hypothesis was explored by addressing physiological and molecular responses to saline-alkaline conditions of $A$. thaliana demes differing in salinity and carbonate tolerance.

Methods A. thaliana native to saline-siliceous soils (G3), to non-saline carbonate soils (G1), or to soils with intermediate levels of these factors (G2) were cultivated in common gardens on saline-siliceous or saline-calcareous substrate. Hydroponics and irrigation experiments confirmed the phenotypes. Growth, mineral concentrations, genome differences, and expression of candidate genes were assessed in the different groups.

Results G3 performed best on saline-siliceous soil and in hydroponics with salinity (pH 5.9). However, G3 was more sensitive to saline-alkaline conditions than G1 and G2. Fitness under saline-alkaline conditions was $\mathrm{G} 2>\mathrm{G} 1>\mathrm{G} 3$ and $\mathrm{G} 2$ best maintained ion homeostasis under alkaline salinity. Whole genome scan did not differentiate among the groups, while distinctive patterns for FRO2, NINJA, and CCB4 were found and confirmed by qPCR.

Conclusion In A. thaliana, salinity tolerance evolved on saline-siliceous soils does not provide tolerance to alkaline salinity. Plants from soils with intermediate conditions (G2) have more plasticity to adapt to alkaline salinity than those locally adapted to these individual stress factors. Higher expression of NINJA and $C C B 4$ may contribute to this better adaptation.

\section{Introduction}

Saline stress is one of the majors constrains in agriculture. Soil salinization is frequently co-occurring with alkalinity, especially under arid and semi-arid climates, in which high evapotranspiration rates move an excess of soluble ions like $\mathrm{Na}^{+}, \mathrm{Ca}^{2+}, \mathrm{Mg}^{2+}, \mathrm{K}^{+}, \mathrm{CO}_{3}{ }^{2-}$ and $\mathrm{HCO}_{3}{ }^{-}$to the superficial soil layers. Moreover, soil salinization may destroy soil structure and cause changes in the biological activity (Singh, 2021). Besides natural causes, human activities like crop irrigation are adding more soluble salts to the soils. Including both the natural and anthropogenic origin, it is estimated that 831 million hectares of the Earth are covered by saline-alkaline soils (FAO, 1973). On these soils, plants need to cope with the deleterious effects of both high $\mathrm{pH}$ and excess of salts. Salinity causes both ion toxicity and osmotic effects. Plant adaptive mechanisms towards $\mathrm{NaCl}$ salinity are well established. Sodium enters by NNCs (non-specific channels) reducing the membrane potential. A huge cost of energy is spent to remove salt from the cytosol, store it in the vacuoles, or return it to the apoplast by Salt Overly Sensitive 1 (SOS1). The High Affinity Potassium transporter 1 (HKT1) is an efficient transporter retrieving $\mathrm{Na}^{+}$from the xylem and limiting $\mathrm{Na}^{+}$transport to the shoots (Sandhu et al., 2017). Weak alleles of $H K T 1$ favor leaf $\mathrm{Na}^{+}$ 
accumulation, which may be an advantage under fluctuating and moderate saline conditions through contribution to ABA signaling and osmotic adjustment (Busoms et al., 2018).

The presence of high carbonate and bicarbonate levels affects soil micronutrient availability, especially Fe and Zn (Marschner 1995); moreover, it alters the root cell membrane potential further enhancing nutrient deficiencies. Carbonate/bicarbonate stress causes an imbalance in the plant carbon metabolism due to dark fixation of $\mathrm{CO}_{2} / \mathrm{HCO}_{3}{ }^{-}$(Poschenrieder et al., 2018). The observed enhancement of the production of organic acids and an inhibition of iron translocation from roots to shoots may be a consequence (Alhendavi et al., 1997). Better mobilization of Fe from alkaline soil by root exudation of catechol groups bearing phenolics has been identified as a key process in tolerance to alkaline soils in $A$. thaliana (Terés et al., 2018). Higher expression of FRO2 and IRT1 conveys tolerance to iron deficiency (Connolly et al., 2003). Tolerance to alkaline salinity has been less explored. However, several studies performed with different plant species show more destructive effects of salinity under high pH than under neutral conditions (Gao et al., 2014; Zhang et al. 2017b; Chumnakthong et al. 2019).

The mechanisms behind these synergistic effects are still not clearly established. Double stress has a strong influence on the root architecture. In comparison to $\mathrm{NaCl}$ stress alone, the root architecture of Lotus tenuis changed to a more herringbone phenotype under mixed salt-alkaline stress (Paz et al., 2012). Under alkaline-saline conditions a strong inhibition of nutrient uptake, especially nitrate and phosphate, in addition to micronutrient deficiencies and a high $\mathrm{Na}^{+} / \mathrm{K}^{+}$ratio may injure sensitive plants more than saline stress caused by $\mathrm{NaCl}$ under neutral or slightly acidic conditions (Gao et al., 2014). As under saline stress alone, the capacity to accumulate compatible solutes is a key feature of tolerance to saline alkaline conditions. Enhancement of proline (Shi and Sheng, 2005), betaine, and soluble sugar concentrations are quantitively the most important changes of osmotically active substances (Wang et al., 2018).

Halophytes have evolved extreme tolerance to saline conditions. Geochemical modelling using species distribution models for Australian grass species suggests a correlation between salt and alkalinity tolerance (Saslis-Lagoudatis et al., 2015). In fact, many well-known halophytes have evolved under extreme saline -alkaline conditions (Akhani, 2006). These extreme habitats are characterized by the presence of sodium carbonate, an extreme electrical conductivity of more than $4 \mathrm{dS} \mathrm{m}^{-1}$, and a percentage of exchangeable sodium higher than $15 \%$. Lab studies with alkaline tolerant halophytes have used experimental exposures up to $400 \mathrm{mM} \mathrm{NaCl}$ and pH values up to 10 (Yang et al., 2007; Hajiboland et al., 2018). Such conditions are far beyond the tolerance limits of most crop plants and of the genetic model $A$. thaliana (Hajiboland et al., 2018). Tolerance mechanisms revealed in studies with these halophytes are of interest for both basic plant biology and halophyte agriculture, but may be less relevant for the improvement of major crop species which are mainly glycophytes.

There is relatively little information on the mechanisms underlying tolerance differences to saline stress under alkaline conditions in crop plants. In Oryza sativa, relative expressions of HKT1 and SOS1 were compared between two contrasting lines differing in alkaline-saline stress tolerance. Tolerant lines were 
able to more efficiently limit $\mathrm{Na}^{+}$accumulation in the leaves by higher activation of both genes in comparison to sensitive lines. Furthermore, Fe acquisition and rhizosphere acidification genes were highly induced to maintain plant nutrient homeostasis (Chuamnakthong et al., 2019). Exploring tolerance mechanisms in natural populations of the model plant $A$. thaliana locally adapted to moderate levels of salinity and alkalinity may provide insights into the underlying genetic background that will be useful in crop breeding.

Differences in the tolerance to salinity and moderate carbonate levels as individual stress factors have been described among natural populations of $A$. thaliana in the NE part of Catalonia (Busoms et al. 2015; Terés et al. 2019). Reciprocal transplant and common-garden experiments comparing genetically distinct populations under identical environmental conditions are efficient tools to discriminate the effects of genetic and environmental variations on the phenotype (Johnson et al., 2021). Using such approaches, we have previously shown that coastal populations of $A$. thaliana perform better under salinity than inland populations. However, these studies were performed on siliceous substrate. Inland populations native to areas located close to limestone soils performed better on non-saline, calcareous soil with a moderate carbonate content than coastal plants evolved on siliceous saline soils. The species distribution model elaborated by Busoms (2015) predicted the lack of $A$. thaliana in saline-alkaline soil from this region and several surveys in different years confirmed this model prediction (unpublished data). The distribution of $A$. thaliana is disrupted at coastal locations with saline, lime-rich soils. This indicates that tolerance to saline alkaline field conditions has still not evolved in this species. Nonetheless, the presence of tolerance mechanisms to moderate saline or alkaline conditions as individual stress factors in our $A$. thaliana populations makes these plants an ideal material for exploring the involvement of these tolerance mechanisms to alkaline salinity resistance.

Thus, the objective of this study was to examine the contribution of individual saline and alkaline tolerance mechanisms to the tolerance to the double stress. For this purpose, we analyzed germination, growth, and reproductive fitness of $A$. thaliana demes differing in saline and alkaline tolerance. Common gardens under greenhouse conditions using saline and saline-alkaline soils were performed. Plant responses using hydroponics and plates under controlled conditions were used to validate responses of soil-grown plants. The contribution of selected genes to differences in tolerance was approached by qPCR. These candidate genes were selected based on previous genome scans and GWAS experiments (unpublished data).

\section{Materials And Methods}

\section{Plant and soil materials}

In previous studies, natural variation of Arabidopsis thaliana populations from Catalonia was tested in a multi-year small-scale common garden under saline and carbonated conditions (Busoms et al., 2015; Terés et al., 2019). Seeds from reciprocal transplant experiments performed in 2015 were stored under cold $\left(4^{\circ} \mathrm{C}\right)$ and dry conditions until the beginning of the experiments. Col-0 seeds were included as a 
reference genome and they were purchased from Nottingham Arabidopsis Stock Centre NASC (Scholl, May, and Ware 2000). Prior to use, seeds were surface sterilized by soaking in $70 \%(\mathrm{v} / \mathrm{v})$ ethanol for 1 min, suspended in 30\% (v/v) commercial Clorox bleach and 1 drop of Tween-20 for 5 min and rinsed 5 times in sterile $18 \mathrm{M} \Omega$ milli-Q water. Seeds were stratified for 4 days at $4^{\circ} \mathrm{C}$ to synchronize germination.

Soils from the native Catalan populations of $A$. thaliana were sampled, excavated at $10 \mathrm{~cm}$ depth and transported to the laboratory for further analysis. For the greenhouse experiments, soils from two different locations of the Catalan coast were excavated and transported to the greenhouse at the Universitat Autonòma de Barcelona (UAB). The saline siliceous soil was excavated at Blanes $\left(41^{\circ} 53^{\prime} 42^{\prime \prime} \mathrm{N}\right.$ $\left.3^{\circ} 01^{\prime} 11^{\prime \prime E}\right)$, while the saline-alkaline soil was obtained from l'Escala $\left(42^{\circ} 13^{\prime} 03^{\prime \prime} \mathrm{N} 3^{\circ} 11^{\prime} 30^{\prime \prime} \mathrm{E}\right)$.

GIS data extrapolation

In order to estimate the geologic, edaphic and climatic parameters of each habitat of the $A$. thaliana natural populations, native soil, coordinate locations and public maps from the Institut Cartogràfic i Geològic de Catalunya (ICGC) and the European Soil Data Centre (ESDAC) database (Panagos et al., 2012) were combined using Miramon v8 (Pons, 2004) and Q-GIS (http://qgis.osgeo.org). Maps of soil properties at European scale, based on Lucas 2009/2012 topsoil data, were used to extract the following variables: $\mathrm{pH}$ (measured in $\left.\mathrm{H}_{2} \mathrm{O}\right)$, cation exchange capacity $(\mathrm{CEC})$, and calcium carbonates $\left(\mathrm{CaCO}_{3}\right)$ (Ballabio et al., 2019).

Soil physical and chemical analyses

Six independent samples of each soil type were used. The soil characterization was performed on airdried 2-mm fraction samples. For measurement of soil pH and electric conductivity (EC) $25 \mathrm{ml}$ of $18 \mathrm{M} \Omega$ water were added to $10 \mathrm{~g}$ soil in a Falcon tube. After mixing at constant rotation for $30 \mathrm{~min}, \mathrm{pH}$ measured using a pH-meter (Basic 20+, Crison, Barcelona. Spain) and CE was determined with a conductometer (Hanna, Woonsocket, Rhode Island, USA) (Sonmez et al., 2008). Texture, water holding capacity (WHC) and organic matter was determined following the methods described by Porta (2006). Calcium carbonate content (\%) was measured according to Loeppert et al., (1996).

To determine the available mineral nutrient concentrations, 5 grams of soil were dried at $60^{\circ} \mathrm{C}$ for 48 hours in 50-mL Falcon tubes. Each sample was diluted to $6.0 \mathrm{~mL}$ with DTPA-NH $\mathrm{N}_{4}$ and analyzed for $\mathrm{B}, \mathrm{Ca}$, $\mathrm{Co}, \mathrm{Cu}, \mathrm{Fe}, \mathrm{K}, \mathrm{Mg}, \mathrm{Mn}, \mathrm{Mo}, \mathrm{Na}, \mathrm{Ni}, \mathrm{P}, \mathrm{S}$, and $\mathrm{Zn}$ on an ELAN-DRCe ICP-MS instrument (PerkinElmer, Sciex). National Institute of Standards and Technology (NIST) traceable calibration standards (ULTRA Scientific) were used for calibration (Soltanpour and Schwab, 1977).

Plant ionome

Plant material was dried for 4 days at $60^{\circ} \mathrm{C}$. Approximately $0.1 \mathrm{~g}$ was used to perform and open-air digestion in Pyrex tubes using $0,7 \mathrm{~mL}$ concentrated $\mathrm{HNO}_{3}$ at $110^{\circ} \mathrm{C}$ for $5 \mathrm{~h}$ in a hot-block digestion system (SC154-54-Well Hot Block ${ }^{\mathrm{TM}}$, Environmental Express, SC, Charleston, USA). The concentrations of 
the following elements ( $\mathrm{Ca}, \mathrm{K}, \mathrm{Mg}, \mathrm{Na}, \mathrm{P}, \mathrm{S}, \mathrm{B}, \mathrm{Mo}, \mathrm{Cu}, \mathrm{Fe}, \mathrm{Mn}$ and $\mathrm{Zn}$ ) were determined by inductively coupled plasma optical emission spectroscopy ICP-OES (Thermo Jarrell-Ash, model 61E Polyscan, England) (Soltanpour and Schwab, 1977).

\section{Greenhouse experiment}

In January 2019, 19 A. thaliana demes and Col-0 were sown in contrasted saline and saline-alkaline soil. Five seeds of each deme were sown in 30 pots (15 of each soil type) and distributed randomly in the greenhouse. Two weeks after germination, seedlings were thinned out so that only one plant per pot was left. Irrigation was applied twice a week. Every week, pictures of the entire rosette were taken. Siliques number was counted at plant maturity. Air temperature, humidity and sun incidence were monitored throughout the experiment.

Salinity-alkalinity tolerance assays

Plate culture For germination assays, sterilized seeds from each deme were sown in plates under a flow cabinet with sterile material. Plates contained 4 treatments: control $(1 / 2 \mathrm{MS}, \mathrm{pH} 5.9)$, neutral salinity $(1 / 2 \mathrm{MS}$ $\mathrm{NaCl} 50 \mathrm{mM}, \mathrm{pH} 5.9)$, alkalinity ( $\left.1 / 2 \mathrm{MS} 10 \mathrm{mM} \mathrm{NaHCO}_{3}, \mathrm{pH} 8.3\right)$, and alkaline-saline treatment $(1 / 2 \mathrm{MS} \mathrm{NaCl}$ $40 \mathrm{mM}+10 \mathrm{mM} \mathrm{NaHCO}_{3}, \mathrm{pH}$ 8.3). For each deme and treatment, a total of 60 seeds were divided among 4 plates. All plates contained Phyto-agar 0.6\% (Duchefa, Haarlem, The Netherlands), and solutions were buffered using different proportions of MES and BTP depending on final pH. Plates with seeds were kept at $4^{\circ} \mathrm{C}$ for synchronizing germination. After 4 days under stratification treatment, plates were moved to a

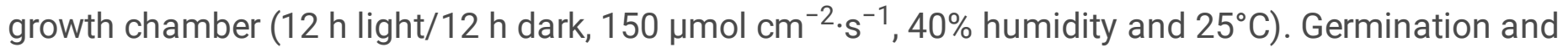
radicle emergence were daily checked using a stereomicroscope (Model, Leica, Wetzlar, Germany) during the following 10 days.

Hydroponic experiment Sterilized seeds of demes from 6 coastal (G3), 4 intermediate (G2), 4 inland (G1) demes were sown in $0.2 \mathrm{~mL}$ tubes containing $0.6 \%$ agar prepared with nutrient solution $1 / 2$ strengthHoagland ( $1 / 2 \mathrm{HS}, \mathrm{pH} 5.9)$. Seeds were kept at $4^{\circ} \mathrm{C}$ for 4 days in the dark to synchronize germination and placed in the growth chamber ( $12 \mathrm{~h}$ light $/ 12 \mathrm{~h}$ dark, $150 \mu \mathrm{mol} \mathrm{cm}{ }^{-2} \cdot \mathrm{s}^{-1}, 40 \%$ humidity and $25^{\circ} \mathrm{C}$ ). After root emergence (48 hours approximately), the bottom of the tubes containing seedlings was cut off and the tubes were placed in $150 \mathrm{~mL}$ hydroponic containers with aerated nutrient solution $1 / 2 \mathrm{HS}$ (pH 5.9). Nutrient solution was replaced every 2 to 3 days to maintain a constant concentration of nutrients in the solution. When 15 days old, the seedlings were separated into different sets. To avoid osmotic shock, the treatment solutions were gradually increased in each set to achieve the final treatment conditions after one week. The following treatments were applied: control ( $1 / 2 \mathrm{HS}, \mathrm{pH} 5.9)$ and two alkaline-saline treatments $\left(1 / 2 \mathrm{HS}+\mathrm{NaCl} 40 \mathrm{mM}+10 \mathrm{mM} \mathrm{NaHCO}_{3}, \mathrm{pH} 8.3\right)$ and $\left(1 / 2 \mathrm{HS}+\mathrm{NaCl} 60 \mathrm{mM}+15 \mathrm{mM} \mathrm{NaHCO}_{3}\right.$, $\mathrm{pH}$ 8.3). Solutions were buffered with different proportions of MES and BTP. Control and treatments solutions were replaced every 3 days. Plants remained in these conditions for two weeks. Every third day, pictures of the entire plants were taken. 37-days old plants were harvested and leaves and roots were 
pictured, weighted and stored at $-80^{\circ} \mathrm{C}$. Rosette diameters were scored and the length of the largest root of each plant was measured using ImageJ software (Bourne 2010; Schneider et al. 2012).

Irrigation experiment Plants from A1 (G1), T6 (G3), LG5 (G2), V1 (G2)V3 (G2) demes and Col-0 (REF) were cultivated individually in square pots of $10-\mathrm{cm}$ diameter in sterilized quartz sand. Sterilized seeds were sown on wet soil and the pots were covered with polyvinyl chloride film until the seedlings had germinated. Pots with germinated seedlings were placed in a growth chamber with 12-h-light/12-h-dark photoperiod, an irradiance of $150 \mathrm{mmol} \mathrm{m}^{-2} \mathrm{~s}^{-1}$, and a constant temperature of $22^{\circ} \mathrm{C}$. Plants were watered with $1 / 4$ strength Hoagland at neutral pH 5.9 solution every 2 to 3 days. After 2 weeks, seedlings of each deme were split into 4 groups and different treatments were applied $(n=8)$. To avoid osmotic shock, the treatment solutions were gradually increased to achieve the final treatment conditions after one week. The applied treatments were: control $(1 / 2 \mathrm{HS}, \mathrm{pH} 5.9)$, salt $(1 / 2 \mathrm{HS}+75 \mathrm{mM} \mathrm{NaCl}, \mathrm{pH} 5.9)$, alkaline $(1 / 2 \mathrm{HS}+$ $\left.15 \mathrm{mM} \mathrm{NaHCO}_{3}, \mathrm{pH} 8.3\right)$, and alkaline-saline conditions $\left(1 / 2 \mathrm{HS}+60 \mathrm{mM} \mathrm{NaCl}+15 \mathrm{mM} \mathrm{NaHCO}_{3}, \mathrm{pH} 8.3\right)$. Solutions were buffered with different proportions of MES and BTP. After 2 weeks under treatment conditions, plant material was collected. Roots were carefully rinsed with deionized water and fresh weight of each organ was measured prior to store at $-80^{\circ} \mathrm{C}$. A detailed outline of the experimental designs is shown in Supplementary Fig. S1.

\section{Gene expression analysis}

Frozen leaf material of plants from the irrigation experiments was used for RNA extraction. Total RNA was extracted using PROMEGA RNA plant kit and following manufactured instructions. Total RNA was used to produce cDNAs using the iScriptTM cDNA Synthesis Kit (Bio-Rad, Hercules, CA, USA) with $1 \mu \mathrm{L}$ iScript Reverse Transcriptase $+4 \mu \mathrm{L} 5 \mathrm{x}$ iScript Reaction Mix + Sample + Molecular Water to obtain $20 \mu \mathrm{L}$ volume. Samples were run in a thermocycler (48-well MJ MiniTM, Bio-Rad, Hercules, CA, USA) for 5 min at $25^{\circ} \mathrm{C}, 30 \mathrm{~s}$ at $42^{\circ} \mathrm{C}$, and $5 \mathrm{~s}$ at $85^{\circ} \mathrm{C}$. Dilution of the cDNAs was performed 1:50 with water (Molecular Biology Reagent, Sigma-Aldrich, St. Louis, MO, USA). Diluted cDNA (1:50) was used as a template for quantitative PCRs using iTaq Universal SYBR Green Supermix (Bio-Rad, Hercules, CA, USA). Real-time detection of fluorescence emission was performed on a CFX384 Real-Time System (Bio-Rad, Hercules, CA, USA) using the following conditions: denaturalization step for $10^{\prime \prime}$ at $95^{\circ} \mathrm{C}$ followed by annealing and extension for $30^{\prime \prime}$ at $60^{\circ} \mathrm{C}$. A total of 40 cycles were run. A melt curve was performed, increasing from $65.0^{\circ} \mathrm{C}$ to $95.0^{\circ} \mathrm{C}$ by $0.5^{\circ} \mathrm{C}$ each 5 seconds. Plates were edited using the CFX manager version 3.1 software. Primers from selected genes were designed using NCBI primer blast tool (Ye et al., 2012). The sequences of primers used are detailed in Supplementary Dataset S1. The expression of target genes was normalized to the expression level of the Actin2 and Tubulin genes of A. thaliana (Dekkers et al. 2012). The relative expression (RE) of each gene was calculated in comparison to the control treatment. The expression of the target gene relative to the expression of the reference gene was calculated using the $2-\Delta \Delta$ Ct method (Livak and Schmittgen, 2001).

\section{Statistical analysis}


For the hierarchical clustering of the Catalan $A$. thaliana demes, we generated a progressive alignment of 37574 SNPs for the whole-genome tree of 75 plants from (Busoms et al., 2018). For the clustering of CCB4, NINJA, FRO2 and SOS1 genes the alignment was generated with 134, 25, 37 and 28 SNPs respectively. Pairwise genetic distance between individuals and between demes was calculated using the Maximum Likelihood statistical method and the Jukes-Cantor substitution model.

Data normality was checked for all phenotypes and non-normal data were transformed before applying any parametrical tests. Mean-standardized values $(1<$ value $>1)$ of elemental contents of soil and leaf material were used to represent the radar plots and compare each group.

One-way or multivariate ANOVA was used to test for significant differences $(p$-value $<0.05)$ between means of fitness, elemental contents of soil and leaf material, and gene expression. To test for correlations between two variables, a bivariate fit was applied. To perform multiple comparisons of group means we used Tukey's HSD. The phenotypic plastic responses of different $A$. thaliana groups were expressed by their slopes of growth (rosette diameter) in the soil reciprocal transplant and their plasticity was shown by the absolute values of the slopes. All the statistical analyses were performed using the SAS Software JMP v.16.0 (https://www.jmp.com/es_es/home.html).

\section{Results}

Distribution of native $A$. thaliana demes according to climate, soil and genetic characteristics

The A. thaliana demes used in this study occur spontaneously in the North-East of the Iberian Peninsula (Fig. 1A), which corresponds to the southern edge of the distribution area of this species (Krämer, 2015). Almost all Catalan $A$. thaliana populations are placed in the same climatic region which corresponds to the Mediterranean coastal climate. Coastal and inland demes have been distinguished based on the salinity concentrations in the soils (Busoms et al., 2015). However, the distribution of $A$. thaliana demes is clearly interrupted in the saline alkaline areas of the coast (dark green areas in Fig. 1A). Soils in these areas have high salinity, high $\mathrm{pH}$ and high carbonate contents (Supplementary Fig. S2 B-D). Coastal populations only occur on siliceous substrate (Supplementary Fig. S2A). Previous work has provided evidence that Arabidopsis populations from this region harbor substantial genetic variability and adaptive variation to elevated salinity (Busoms et al., 2015, 2018) and to moderate soil carbonate content (Terés et al, 2019). According to the $\mathrm{Na}^{+}$and $\mathrm{CaCO}_{3}$ concentrations of their native soils, the $A$. thaliana demes were split into three categories: G1-plants from soils with high $\mathrm{CaCO}_{3}$ contents and low salinity (average values $9.4 \% \mathrm{CaCO}_{3}, 44 \mathrm{Na}^{+} \mathrm{mg} \mathrm{g}^{-1}$ ); G2-plants native to soils with intermediate carbonate levels and salinity $\left(5.7 \% \mathrm{CaCO}_{3}, 61 \mathrm{Na}^{+} \mathrm{mg} \mathrm{g}^{-1}\right)$; and $\mathrm{G} 3$-plants from soils with low $\mathrm{CaCO}_{3}$ contents and high salinity $\left(0.65 \% \mathrm{CaCO}_{3}, 129 \mathrm{Na}^{+} \mathrm{mg} \mathrm{g}^{-1}\right)$ (Fig. 1B).

Native soil parameters monitored during 2013 to 2015 (Busoms, 2015) were used as input to perform a Principal Component Analysis (PCA). Soil Na, Mg, Mo, chlorides and sulphates groups G3 demes, while $\mathrm{Fe}, \mathrm{Zn}, \mathrm{K}, \mathrm{P}, \mathrm{pH}, \mathrm{CaCO}_{3}$ and $\mathrm{WHC}$ differentiate $\mathrm{G} 1$ demes (Fig. 1C). Correlations between the different 
parameters of the native soils ( $\mathrm{pH}, \mathrm{OM}, \mathrm{WHC}$ and nutrients) can be found in Supplementary Dataset S3. Fig. 1D represents the mean relative values of available mineral nutrients in the native soil of each group. $\mathrm{G} 1$ soil was characterized by higher $\mathrm{Na}^{+}, \mathrm{Mg}$ and $\mathrm{Cl}$ concentrations, while higher $\mathrm{K}^{+}$concentrations were found in soils from G2 and G3. Phosphorus, Zn and Ni concentrations were higher in G3 than in G2 with intermediate levels of carbonate and salinity (Supplementary Dataset S3).

Hierarchical clustering of the whole-genome tree of 74 individuals did not reveal a clear population structure defining the three established groups (Fig. 1E). The native soils characteristics do not provide a genome-wide differentiation and several lineages are present in different habitats. Despite we do not observe genotypic differentiation by geography, the distance between some demes of the G2 (around 60 $\mathrm{km}$ apart) explains why they cluster in two different nodes.

Reciprocal soil transplant experiment

To reveal potential differences in fitness among demes in response to salinity on alkaline or siliceous substrate, a reciprocal soil transplant experiment was established in a greenhouse. Plants were grown from seeds in pots filled either with saline-siliceous or saline-alkaline soil. Both soils had a similar sandyloam texture and salinity levels, but clearly differ in $\mathrm{pH}(6.5$ vs. 8.4$)$ and carbonate content ( $2 \%$ vs. $18 \%)$ (Supplementary Fig. S3A). The nutrient availability of both soils was also considerable different. Higher $\mathrm{Fe}, \mathrm{Zn}, \mathrm{Mn}$, and $\mathrm{Mg}$ concentrations were found in the saline-siliceous soil, while $\mathrm{Na}^{+}$and $\mathrm{K}^{+}$ concentrations were similar in both (Supplementary Fig. S3B and Dataset S4).

Plant fitness was assessed measuring rosette diameter of 5 weeks old plants (Fig. 2A) and the number of siliques per plant at maturity (Fig. 2B). On saline-siliceous soil, plants of G3, native to saline siliceous soils, performed better than plants from G1 or G2 (Fig. 2A, B). Contrastingly, on saline-alkaline soil best performance was observed for $\mathrm{G} 2$ plants, native to soils with intermediate levels of salinity and alkalinity. Plants adapted to saline-siliceous soils suffered severe reduction of growth and number of siliques when cultivated on saline-alkaline soil (Fig. 2A, B and Supplementary Dataset S5). The plasticity index based on rosette diameter shows that plasticity is a major factor responsible for the better growth of $\mathrm{G} 2$ plants on alkaline-saline soil. Contrastingly, G3 plants were maladapted to alkaline-saline conditions, while G1 plants revealed low plasticity (Fig. 2C).

Plants from different groups also differed in the relative leaf ion concentrations when grown on the contrasting soils (Fig. 2E, F and Supplementary Dataset S6). Plants adapted to saline-siliceous soils (G3) were able to maintain higher $\mathrm{K}^{+}$concentrations on saline-siliceous soil than plants from $\mathrm{G} 1$ and $\mathrm{G} 2$, while concentrations of Mo and P were considerably lower in G3 plants (Fig. 2F). On the saline-alkaline soil, G2 plants maintained higher leaf concentrations of all analyzed nutrients (Fig. 2F). Sodium concentrations were similar in G2 and G3 plants; only G1 plants restricted better the Na transport to the leaves.

Saline-alkaline stress experiments 
To further confirm the differential responses of the $A$. thaliana demes to saline-alkaline conditions, germination tests and hydroponic cultures were performed. Under control conditions (no $\mathrm{NaCl}, \mathrm{pH} 5.9$ ), the germination rates determined on agar plates did not differ among the three groups. Moderate salinity $(50 \mathrm{mM} \mathrm{NaCl})$ applied at slightly acidic $\mathrm{pH}(\mathrm{pH}$ 5.9) somewhat reduced the germination rates in all three groups to similar extent. Contrastingly, under non-saline alkaline conditions (10 $\mathrm{mM} \mathrm{NaHCO}_{3}, \mathrm{pH} 8.3$ ) germination rates were higher in demes native to soils with the highest carbonated level (G1) and lowest in demes locally adapted to salinity on siliceous soil (G3). The saline-alkaline treatment $(40 \mathrm{mM} \mathrm{NaCl}+$ $10 \mathrm{mM} \mathrm{NaHCO}_{3}$ ) almost completely inhibited germination of $\mathrm{G} 3$ plants, while in $\mathrm{G} 1$ and $\mathrm{G} 2$ demes germination rates were similar to those observed with $\mathrm{NaCl}$ salinity under slightly acidic $\mathrm{pH}$ conditions (Fig. 3A). The germination rates of the demes under the alkalinity treatment were positively correlated to the soil carbonate content in their native habitats, but negatively related to the corresponding soil $\mathrm{Na}^{+}$ contents. A negative correlation between germination rate and native soil $\mathrm{Na}^{+}$was also observed for the alkaline-saline treatment (Supplementary Dataset S7).

For growth performance under saline alkaline conditions, two levels of stress were assayed: a moderate stress level with $40 \mathrm{mM} \mathrm{NaCl}+10 \mathrm{mM} \mathrm{NaHCO} 3(\mathrm{pH} 8.3)$ and a strong level with $60 \mathrm{mM} \mathrm{NaCl}+15 \mathrm{mM}$ $\mathrm{NaHCO}_{3}$ (pH 8.3). The strong treatment reduced root and leaf length in all three groups (Fig. 3B). Under the moderate saline-alkaline stress plants from $\mathrm{G} 1$, and $\mathrm{G} 3$ also suffered inhibition of root and leaf elongation, while G2 plants were hardly affected (Fig. 3B, Supplementary Dataset S7). These results confirm the better tolerance of $\mathrm{G} 2$ plants to saline-alkaline stress.

Irrigation experiments and molecular analyses

Further experiments using sand cultures irrigated with different treatment solutions confirmed the superior behavior of $\mathrm{G} 2$ plants under saline-alkaline conditions and the best performance of $\mathrm{G} 3$ plants under saline slightly acidic pH conditions (Fig. 4A; Supplementary Fig. S4). A. thaliana Col-0 plants were included here as a reference. Tolerance to the saline-alkaline treatment of the Col-0 plants was similar to that of G2; only the relative rosette diameter was more inhibited in Col-0.

Based on a previous GWAS performed with the A. thaliana HapMap cohort cultivated in the same salinealkaline soil used here for the reciprocal transplant experiment (unpublished data), we explored the candidate genes associated with leaf $\mathrm{Na}^{+}$and Fe concentrations. We generated a neighbor-joining ( $\mathrm{NJ}$ ) cladogram for each locus and we selected NINJA (Novel Interaction of JAZ) and CCB4 (Cofactor Assembly of Complex $C$ ) because these were the only genes that clustered the majority of $\mathrm{G} 2$ plants in the same node (Fig. 4F, H). Moreover, we included in the analysis two genes, SOS1 (Salt Overly Sensitive 1) and FRO2 (Ferric Reduction Oxidase 2), with a well-established function in tolerance to salinity and $\mathrm{Fe}$ deficiency, respectively. The cladogram of SOS1 revealed no genomic relationship between groups (Fig. 4B) but FRO clustering grouped all G2 plants and one G1 deme (SCF) in the same node (Fig. 4D), suggesting that $F R O 2$ can have a role in saline-alkaline tolerance. 
Quantitative PCR analysis of the selected genes performed 10 days after exposure to the different treatment solutions confirmed that SOS1 was enhanced by salinity stress in all plants (Fig. 4C). However, in T6 plants (G3) this gene was highly expressed in the plants submitted to salinity but not in the ones exposed to saline-alkaline stress. Interestingly, in the rest of plants SOS1 expression was equally high in the plants submitted to the saline-alkaline treatment (Fig. 4C). Regarding FRO2, the alkalinity treatment enhanced the expression in all plants, but the salt-alkaline exposure only increased the expression of FRO2 in the $\mathrm{G} 2$ plants (Fig. $4 \mathrm{E}$ ). A similar pattern was observed for the CCB4 gene. CCB4 was significantly enhanced by saline-alkaline stress only in $\mathrm{G} 2$ plants (Fig. $4 \mathrm{G}$ ). Alkalinity also raised the expression of $C C B 4$ in Col-0 and A1 (G1) plants, suggesting that this gene is activated due to the presence of bicarbonate. It is well-known that abiotic stresses activate plant defense hormones like jasmonic acid (JA). NINJA encodes part of a repressor complex that negatively regulates JA signaling (Acosta et al., 2013). We detected that NINJA was enhanced in G2 plants under all the treatments but especially under alkaline salinity (Fig. 4I).

\section{Discussion}

It is already established that saline-alkaline conditions are more stressful to plants than salinity under slightly acidic or neutral pH conditions (Shi et al., 2005; Gao et al. 2014). Our results confirm sensitivity to saline-alkaline conditions of both demes locally adapted to salinity on siliceous soils and those locally adapted to non-saline carbonated soil (Figs. 2 and 3). Even so, most studies addressing the molecular genetic mechanisms underlying salinity tolerance in $A$. thaliana are performed under slightly acidic $\mathrm{pH}$ (e.g., DeRose-Wilson and Gout, 2011; Busoms et al., 2015); many authors do not even mention the pH conditions of the treatments (e.g. Julkowska et al., 2016; Liu et al., 2020), and studies with A. thaliana seldomly include bicarbonate in the saline treatment solutions (e.g. Jia et al., 2017).

Local adaptation to soil conditions in NE Catalonia

In NE Catalonia $A$. thaliana demes have a particular distribution. In previous studies we have shown that soil $\mathrm{Na}^{+}$drives divergent selection of coastal demes with higher tolerance to salinity (Busoms et al., 2015). These demes (G3) occur all on siliceous saline soils. Soil carbonate $(\mathrm{pH}>7)$ is a further factor for local adaptation of $A$. thaliana at non-saline inland sites (G1 demes) (Terés et al., 2018) (Fig. 1A). Based on soil characteristics and phenotype data, here we defined a third group of plants (G3) from habitats with intermediate soil levels of $\mathrm{Na}^{+}$and carbonate (Fig. 1B). However, no A. thaliana demes were found under the harsh conditions of coastal saline-alkaline habitats with high $\mathrm{Na}^{+}$and carbonate concentrations. This is illustrated by the fact that the distribution of $A$. thaliana demes on the Catalonian coast is restricted to saline-siliceous soils on plutonic rocks and interrupted characteristically on coastal calcareous dolomites, limestones, sandstones and gypsum (Fig. S2A). This distribution indicates that in this region local adaptation to strong saline-alkaline conditions has still not evolved in $A$. thaliana.

Plants able to adapt to alkaline-saline conditions must efficiently manage multiple stress factors: high $\mathrm{Na}^{+}$, low osmotic potential, low availability of micronutrients, especially Fe and Zn, and imbalance of 
carbon metabolism due to dark fixation of inorganic carbon (Poschenrieder et al., 2018). PCA analysis using physico-chemical characteristics of the native soils of the $A$. thaliana demes analyzed here confirm the clear separation of the three plant groups (Fig. 1C). Chloride content, sulfate and $\mathrm{Mg}, \mathrm{Mo}$ and $\mathrm{Na}$ are correlated, and they overlap with the coastal populations, while $\mathrm{Ca}, \mathrm{Zn}$ and $\mathrm{P}$ concentrations are correlated and are characteristic for the alkaline soils. Differences in the relative availability of soil nutrients among the habitats further characterize the three plants groups (Fig. 1D).

Although soil $\mathrm{Na}^{+}$and carbonate concentrations clearly distinguish $\mathrm{G} 1$ and $\mathrm{G} 3$ demes and we previously have shown that these soil factors drive local adaptation in $A$. thaliana demes in this region (Busoms et al., 2015; Terés et al., 2018), the whole-genome tree does not reveal a clear stratification by soil of the 3 groups (Fig. 1E). Contrastingly phenotype differences were evident both in greenhouse common gardens and hydroponics (Figs. 2 and 3).

Phenotype differences under saline-alkaline stress

Although $A$. thaliana is unable to colonize the saline-alkaline soils of the Catalonian coast, plants from all three groups were able to grow in common gardens on such alkaline saline-soil under greenhouse conditions. The lack of competition in the experimental pots and the regular irrigation to field capacity provided less stressful conditions. A main obstacle for coastal demes from siliceous soils to colonize the nearby saline alkaline soils seems to be the strong inhibition of the germination rate (Fig. $3 \mathrm{~A}$ ). Synergistic effects of salinity and alkalinity on germination have previously been reported in alfalfa cultivars differing in alkaline-saline tolerance (Zhang et al., 2017a); germination and early growth stages are also the most sensitive in wheat (Lin et al., 2012). All A. thaliana demes suffered inhibition of germination on alkaline-saline substrate. G3 plants were most severely inhibited, while G1 and G2 plants had similar germination rates (Fig. 3A).

Subsequent growth of germinated transplanted seedlings to hydroponics revealed better performance of G2 plants under saline-alkaline conditions. This was especially visible for the mild alkaline-saline treatment $\left(40 \mathrm{mM} \mathrm{NaCl}+10 \mu \mathrm{M} \mathrm{NaHCO}_{3}\right)$ which did not cause any reduction in rosette diameter and root length in the G2 plants native to soils with intermediate levels of salinity and alkalinity (Fig. 3B). Contrastingly, plants native to non-saline alkaline soil (G1) and those native to saline-siliceous soils (G3) suffered from growth inhibition even under the mild alkaline-saline stress treatment. Comparison of relative growth values (Fig. 4A) clearly demonstrates the best performance of G2 under saline-alkaline conditions in contrast to $\mathrm{G} 3$ plants, with best growth under saline, low pH conditions.

Higher performance of $\mathrm{G} 2$ under saline-alkaline stress was also confirmed by the common garden study (Fig. 2A-B). Under saline conditions, G3 plants were best maintaining high $\mathrm{K}^{+} / \mathrm{Na}^{+}$tissue ratios (Fig. $2 \mathrm{~F}$ ). However, under saline-alkaline conditions $\mathrm{G} 3$ plants had the lowest relative $\mathrm{K}^{+}$concentrations. Contrastingly, G2 plants not only maintained high $\mathrm{K}^{+} / \mathrm{Na}^{+}$ratios but also had higher relative concentrations of $\mathrm{Fe}$ and $\mathrm{Zn}$, micronutrients that are often limiting growth of plants under alkaline conditions (Riaz et al., 2020). Maintenance of a high $\mathrm{K}^{+} / \mathrm{Na}^{+}$ratio is critical for salinity tolerance (Rubio et 
al, 2020). Alkaline salinity has an especially severe inhibitory effect on this parameter (Lin et al., 2012). Our results suggest that alkalinity may hamper the transport mechanisms that allow salt tolerant plants to maintain high $\mathrm{K}^{+} / \mathrm{Na}^{+}$ratios under non-alkaline saline conditions.

Transcript expression of selected genes

SOS1 is required for salinity tolerance by maintaining $\mathrm{Na}^{+}$and $\mathrm{K}^{+}$homeostasis in plants exposed to salinity (Shi et al., 2000). Extreme increases of the $\mathrm{Na}^{+} / \mathrm{K}^{+}$ratio in sos 1 rice mutants have been observed, especially in the xylem parenchyma (El Mahi et al., 2019). In our $A$. thaliana demes, SOS1 expression was enhanced by both saline and saline-alkaline treatments in all demes to similar extent. Exceptions were T6 from G3 and V3 from G2, which had considerably higher SOS1 expression under non-alkaline salinity (Fig. 4C). Contrastingly, in saline tolerant rice higher SOS1 expression has been reported under $\mathrm{pH} 8$ than under pH 7 (Chummnathong et al., 2019). The A. thaliana T6 deme has evolved on saline, slightly acidic soil and the highest expression of SOS1 was obtained in slightly acidic saline solutions simulating conditions of the native habitat. The lower expression under alkaline conditions suggests that alkaline salinity is either less perceived by these plants or that other constraints imposed by the alkaline-saline conditions inhibit the full expression of SOS1. SOS1 gene expression is regulated by a complex signaling network (Ji et al., 2013). Recently it has been shown that AtbZIP62 negatively regulates both SOS1 expression (Rolly et al., 2020) and systemic acquired pathogen defense probably mediated by salicylate; but an interplay with alkaline stress has not been shown so far.

FRO2, coding for ferric-chelate reductase plays an important role in plants iron acquisition both in roots and in leaves. The enzyme is responsible for the reduction of Felll prior to transport into the root or leaf cells and its activity is substantially enhanced under Fe deficiency (Connolly et al., 2003). Alkalinity enhanced $F R O 2$ expression more in roots of carbonate tolerant than carbonate sensitive soybean varieties (Waters et al., 2018). Contrastingly, FRO2 expression is decreased in chlorotic leaves of sensitive orange trees exposed to carbonate (Martínez-Cuenca et al., 2017). Under the alkaline non-saline conditions of this study, FRO2 expression was enhanced in all demes; G2 plants achieved the highest values (Fig. 4E). Excepting the G2 deme LG5, FRO2 expression under alkaline salinity was lower than under alkaline stress alone. However, under saline alkaline conditions all G2 plants maintained higher FRO2 expression levels than the reference accession Col-0 and plants from G1 and G3 demes. Natural genetic variants for $F R O 2$ have been reported in $A$. thaliana accessions native to soils differing in $\mathrm{Fe}$ availability in Sweden. Different polymorphisms in long and short root accessions were found (Sathbai et al., 2017). Here we observed similar polymorphisms suggesting that $F R O 2$ might be under selection in our $A$. thaliana demes. Non-coding sequence variation of $F R O 2$ should be further explored to determine if the expression differences found in the saline-alkaline tolerant demes (G2) are associated with particular alleles.

Under saline alkaline stress, transcription of NINJA was characteristically enhanced in all demes, except in T6 adapted to non-alkaline salinity (Fig. 4I). This $\mathrm{G} 3$ deme showed extremely low expression of NINJA under all treatments. NINJA is a key factor in jasmonate signaling; the protein associates with the 
transcription factor ERF19 inhibiting its transcriptional role (Huang et al., 2019). Interestingly, jasmonate has been found to inhibit the expression level of FRO2 (Maurer et al., 2011). We selected NINJA for this expression analysis as a previous GWA study revealed an association between NINJA and the variance in leaf $\mathrm{Na}^{+}$concentrations (unpublished results). Results here indicate that a constitutively low expression of NINJA is associated with low $\mathrm{Na}^{+}$leaf concentrations under saline treatments in T6. Non-alkaline salinity increased NINJA expression in salt sensitive A1 of the G1 group and in Col-0, but not in plants of G2 (Fig. 4I). In these plants tolerant to alkaline-salinity, NINJA expression was substantially enhanced only under saline -alkaline conditions. NINJA, by assembly with FRS proteins, may act as a repressor of glucosinolate (GS) biosynthesis (Fernández-Calvo et al., 2020). In alkaline tolerant $A$. thaliana exposed to bicarbonate we have previously observed upregulation of GS biosynthesis related genes and we proposed that enhanced GS production may be a way to retrieve excessive organic carbon produced by dark fixation of inorganic carbon (Pérez-Martín et al., 2021). This seems not to apply to saline alkaline conditions in $\mathrm{G} 2$ plants where the upregulation of NINJA could repress this induction of GS synthesis. Excess dark-fixed carbon in G2 plants may be used to produce compatible solutes. Osmoprotectants like sugars and anthocyanins accumulate in $A$. thaliana in response to salinity (Leschevin et al., 2021). Moreover, NINJA plays a central role in leaf development (Baekelandt et al., 2018) and therefore the enhanced expression of NINJA in our G2 plants allows a better growth under stress conditions.

Under saline-alkaline stress the optimization of an efficient acquisition and use of nutrients is essential. Iron is especially critical (Li et al., 2016). Under these conditions, G2 plants were able to maintain better leaf Fe concentrations (Fig. 2F). Adjustment of number of photosynthetic cells to the available Fe and preferential allocation of $\mathrm{Fe}$ into the thylakoid membranes seem essential for avoidance of chlorosis development (Terry and Zayed, 1995). Heme proteins are a major sink for chloroplast Fe (Kroh and Pilon, 2020). Cytochrome $b_{6} f$, one of these heme proteins, is a major target for Fe deficiency (Hantzis et al., 2018). Cytochrome $b_{6} f$ plays a key role not only in the lineal electron transfer between PSII and PSI, but also is crucial in cyclic electron transport, in avoidance of ROS damage, and acting as redox sensor (Malone et al., 2021). Under alkaline-saline stress, here we found a considerable upregulation of CCB4 expression specifically in plants of G2 (Fig. 4G). CCB4 is a key protein in the formation of the functional cytochrome $b_{6} f$ as it is required for incorporation of heme into the apoprotein (Schöttler et al., 2015). A key role for CCB4 in alkaline saline tolerance of $A$. thaliana is further supported by the observation that the neighbor joining cladogram for $C C B 4$ clustered all $\mathrm{G} 2$ demes in the same group (Fig. 4F). Moreover, the truncated CCB4 allele found in T6 may explain the lower expression of CCB4 in these plants (Supplementary Fig. S5).

\section{Plasticity}

Local adaptation is a fixed genetic variation that provides an advantage to one specific climatic and/or edaphic condition (Valladares et al. 2014; Josephs 2018). In NE Catalonia we have previously shown that G1 and G3 demes are locally adapted to non-saline alkaline soil and to non-alkaline saline soils, respectively. Here we found superior performance of $\mathrm{G} 2$ plants under moderate alkaline-saline conditions 
in greenhouse and hydroponic experiments. However, these demes native to habitats with intermediate levels of carbonate and $\mathrm{NaCl}$ are not locally adapted to the harsh natural conditions of the alkaline-saline soils of the Catalonian coast. The analysis of plasticity index in the three plant groups clearly show that plasticity is a major factor responsible for the better growth of G2 plants on alkaline-saline soil (Fig. 2C). Contrastingly, G3 plants were maladapted to alkaline-saline conditions, while G1 plants revealed low plasticity. Plasticity is favored under conditions of large gene flow, while local adaptation is enhanced under limited gene flow (Scheiner, 2013). The demes adapted to non-alkaline salinity on the Catalonian coast are still under divergent selection (Busoms et al., 2015). It is likely that genes with unfavorable influence under alkaline salinity are present in G3 demes adapted to non- alkaline salinity. This view is supported by the observation of low expression of $S O S 1$ and $C C B 4$ under saline alkalinity in T6, a deme of G3. Further identification of genes responsible for the maladaptive behavior of G3 plants under alkaline salinity would be of great interest for crop breeding. The genetic basis of plasticity in plants is still poorly known (Laitinen and Nikoloski, 2019). A possible candidate for the adaptive plasticity based on rosette diameter in $\mathrm{G} 2$ could be NINJA. This gene regulating leaf morphology (Baekelandt et al., 2018) clustered almost all G2 plants in the same node and was significantly enhanced under saline-alkaline conditions (Fig. 4H-I).

In conclusion, Arabidopsis thaliana distribution in the north-east of Spain is disrupted in coastal areas with saline alkaline soils. Under less severe controlled conditions, demes native to sites with intermediate levels of $\mathrm{Na}^{+}$and $\mathrm{CaCO}_{3}(\mathrm{G} 2)$ were observed to be the most tolerant to alkaline salinity. The high sensitivity of G3 plants to saline-alkaline stress suggests that the evolved molecular mechanism conveying tolerance to salinity on siliceous substrates can be detrimental under alkaline conditions. G2 plants with higher plasticity under saline alkalinity stress are able to maintain both higher germination rates and better ion homeostasis under alkaline-saline conditions. The higher expression of several key genes, such as FRO2, CCB4 and NINJA, seem to play a key role in the better tolerance to alkaline -saline stress in $\mathrm{G} 2$. This finding is especially relevant for breeding programs considering salinity tolerance in crops destined to saline soils on limestone parent material.

\section{Declarations}

Acknowledgements Special thanks to Dr. Marina Palmero for helping us in GIS and Rosa Padilla to process ICP field and soil samples

Author contribution CP, SB,LP-M, JB and RT conceived the study. SB,LP-M, MAC, NA and JT performed the experiments. SB,LP-M and CP wrote the manuscript with inputs from all coauthors. All the authors gave final approval for publication.

Funding This work was financially supported by the Spanish Ministry of Science, Innovation and Universities project PID2019-104000RB-I00

Data availability Not applicable. 
Code availability Not applicable.

Declarations Ethics approval Not applicable.

Consent to participate Not applicable.

Consent for publication Not applicable.

Conflicts of interest/Competing interests. The authors declare no competing interest.

Open Access This article is licensed under a Creative Commons Attribution 4.0 International License, which permits use, sharing, adaptation, distribution and reproduction in any medium or format, as long as you give appropriate credit to the original author(s) and the source, provide a link to the Creative Commons license, and indicate if changes were made. The images or other third-party material in this article are included in the article's Creative Commons license, unless indicated otherwise in a credit line to the material. If material is not included in the article's Creative Commons license and your intended use is not permitted by statutory regulation or exceeds the permitted use, you will need to obtain permission directly from the copyright holder. To view a copy of this license, visit http://creativecommons.org/licenses/by/4.0/

\section{References}

1. Acosta IF, Gasperini D, Chételat A et al (2013) Role of NINJA in root jasmonate signaling. PNAS 17:110::15473-15478. https://doi.org/10.1073/pnas.1307910110

2. Akhani H (2006) Biodiversity of halophytic and Sabkha ecosystes in Iran. Pp 71-88 In: Sabkha Ecosystems. A. Khan, eds. Vol II: West and Central Asia, Springer, Dordrecht ISBN 978-1-4020-5072-5

3. Alhendawi RA, Römheld V, Kirkby EA, Marschner H (1997) Influence of increasing bicarbonate concentrations on plant growth, organic acid accumulation in roots and iron uptake by barley, sorghum, and maize. J Plant Nutr 20:1731-1753. https://doi.org/10.1080/01904169709365371

4. Baekelandt A, Pauwels $L$, Wang $Z$ et al (2018) Arabidopsis leaf flatness is regulated by PPD2 and NINJA through repression of CYCLIND3 genes. Plant Physiol 178:217-232. https://doi.org/10.1104/pp.18.00327

5. Ballabio C, Lugato E, Fernández-Ugalde 0 et al (2019) Mapping LUCAS topsoil chemical properties at European scale using Gaussian process regression. Geoderma 355:113912. https://doi.org/10.1016/j.geoderma.2019.113912

6. Bourne R (2010) Fundamentals of Digital Imaging in Medicine. Springer, London. ISBN 978-1-84882086-9

7. Busoms S, Terés J, Huang XY et al (2015) Salinity is an agent of divergent selection driving local adaptation of Arabidopsis to coastal habitats. Plant Physiol 168:915-929. https://doi.org/10.1104/pp.15.00427 
8. Busoms S, Paajanen P, Marburger et al (2018) Fluctuating selection on migrant adaptive sodium transporter alleles in coastal Arabidopsis thaliana. PNAS 115:E12443-E12452. https://doi.org/10.1073/pnas.1816964115

9. Chuamnakthong S, Nampei S, Ueda A (2019) Characterization of $\mathrm{Na}^{+}$exclusion mechanism in rice under saline-alkaline stress conditions. Plant Sci 287:110171. https://doi.org/10.1016/j.plantsci.2019.110171

10. Connolly EL, Campbell NH, Grotz N et al (2003) Overepression of the FRO2 ferric chelate reductase confers tolerance to growthon low iron and uncovers posttranscriptional control. Plant Physiol 133:1102-1110. https://dx.doi.org/10.1104\%2Fpp.103.025122

11. Dekkers BJW, Willems L, Bassel GW et al (2012) Identification of reference genes for RT-qPCR expression analysis in Arabidopsis and tomato seeds. Plant Cell Physiol 53:28-37. https://doi.org/10.1093/pcp/pcr113

12. DeRose-Wilson L, Gout BS (2011) Mapping salinity tolerance during Arabisopsis thaliana germination and seedling growth. PLoS ONE 6:e22832. https://doi.org/10.1371/journal.pone.0022832

13. El Mahi H, Pérez-Hormaeche J, De Luca A et al (2019) A critical role of sodium flux via the plasma membrane $\mathrm{Na}+/ \mathrm{H}+$ exchanger SOS1 in the salt tolerance of rice. Plant Physiol 180:1046-1065. https://doi.org/10.1104/pp.19.00324

14. FAO (1973) Report of the FAO/UNDP regional seminar on reclamations and management of calcareous soils FAO Soils Bulletin 21, Calcareous Soils. FAO-UN Rome. ISBN 92-5-100276-2. https://www.fao.org/3/x5868e/x5868e00.htm

15. Fernández-Calvo P, Iñigo S, Glauser G et al (2020) FRS7 and FRS12 recruit NINJA to regulate expression of glucosinolate biosynthesis genes. New Phytol 227:1124-1137. https://doi.org/10.1111/nph.16586

16. Gao Z, Jianyu H, Chunsheng M (2014) Effects of saline and alkaline stresses on growth and physiological changes in oat (Avena sativa L.) seedlings. No. Bo. Hort Agrobot Cluj-Napoca. 42:: pp. 357-362. https://doi.org/10.15835/nbha4229441

17. Hajiboland R, Bahrami-Rad S, Akhani H, Poschenrieder C (2018) Salt tolerance mechanisms in three Irano-Turanian Brassicaceae halophytes relatives of Arabidopsis thaliana. J Plant Res 131:10291046. https://doi.org/10.1007/s10265-018-1053-6

18. Hantzis LJ, Kroh GE, Jahn CE et al (2018) )A program for iron eonomy during deficiency targets specific Fe proteins. Plant Physiol 176:596-610. http://www.plantphysiol.org/cgi/doi/ 10.1104/pp.17.01497

19. Huang PY, Zhang J, Jiang B et al (2019) NINJA-associated ERF19 negatively regulates Arabidopsis pattern-triggered immunity. J Exp Bot 70:1033-1047. https://doi.org/10.1093/jxb/ery414

20. Ji H, Pardo JM, Batelli G, Van Oosten MJ et al (2013) The salt overly sensitive (SOS) pathway: established and emerging roles Molec Plant. 6:275-286. https://doi.org/10.1093/mp/sst017 
21. Jia B, Sun M, Mu HD et al (2017) GsCHX19.3, a member of cation/H+ exchanger superfamily from wild soybean contributes to high salinity and carbonate alkaline tolerance. Sci Rep 7:9423. https://doi.org/10.1038/s41598-017-09772-3

22. Johnson LC, Galliart MB, Alsdurf JD et al (2021) Reciprocal transplant gardens as gold standard to detect local adaptation in grassland species: New opportunities moving into the 21 st century. $J$ Ecol 00:1-18. https://doi.org/10.1111/1365-2745.13695

23. Josephs EB (2018) Determining the evolutionary forces shaping G x E. New Phytol 219:31-36. https://doi.org/10.1111/nph.15103

24. Julkowska MM, Lei KK, Fokkens $L$ et al (2016) Natural variation in rosette size under salt stress conditions correspond to developmental differences between Arabidopsis accessions and allelic variation in the LRR-KISS gene. J Exp Bot 67:2127-2138. https://doi.org/10.1093/jxb/erw015

25. Krämer $\mathrm{U}$ (2015) The natural history of model organisms:planting molecular functionsin an ecological context with Arabidopsis thaliana. eLife 2015;4:e06100.

https://doi.org/10.7554/eLife.06100.001

26. Kroh GE, Pilon M (2020) Regulation of iron homeostasis and use in chloroplasts. Int J Mol Sci 21:3395. http://dx.doi.org/10.3390/ijms21093395

27. Laitinen RAE, Nikoloski Z (2019) Genetic basis of plasticity in plants. J Exp Bot 70:739-745. https://doi.org/10.1093/jxb/ery404

28. Leschevin $M$, Ismael $M$, Quero A et al (2021) Physiological and biochemical traits of two major Arabidopsis accessions, Col-0 and Ws, under salinity. Front Plant Sci 12:639154. https://doi.org/10.3389/fpls.2021.639154

29. Li Q, Yang A, Zhang WH (2016) Efficient acquisition of iron confers greater tolerance to saline alkaline stress in rice (Oryza sativa L.). J Exp Bot 67:6431-6444. https://doi.org/10.1093/jxb/erw407

30. Lin J, Li X, Zhang Z et al (2012) Salinity -alkalinity tolerance in wheat: seed germination, early seedling growth, ion relations and solute accumulation. Afr J Agric Res 7:467-474. https://doi.org/10.5897/AJAR11.1417

31. Livak KJ, Schmittgen TD (2001) Analysis of relative gene expression data using real-time quantitative PCR and the $2-\Delta \Delta C T$ method. Methods 25:402-408.

https://doi.org/10.1006/meth.2001.1262

32. Liu S, Tian Y, Jia M et al (2020) Induction of salt tolerance in Arabidopsis thaliana by volatiles from Bacillus amyloliquefaciens FZB42 via the jasmonic acid signaling pathway. Front Microbiol 11:562934. https://doi.org/10.3389/fmicb.2020.562934

33. Loeppert RH, Suarez DL (1996) Carbonate and gypsum. Chapter 15 in Methods of Soil Analysis. Part 3, 5 edn. USDA-ARS U.S. Salinity Laboratory, Riverside,California. Texas A\&M University College Station, Texas

34. Malone LA, Proctor MS, Hitchcock A et al (2021) Cytochrome $b_{6} f-$ orchestrator of photosynthetic electron transfer. Biochim Biophys Acta- Bioenergetics 1862:148380. 
https://doi.org/10.1016/j.bbabio.2021.148380

35. Marschner H (1995) Mineral Nutrition of Higher Plants 2nd ed. Academic Press, London. ISBN 0-12473543-6

36. Martínez-Cuenca MR, Primo-Capella A, Quiñones A et al (2017) Rootstock influence on iron uptake responses in Citrus leaves and their regulation under the Fe paradox effect. Peer J 5:e3553. https://doi.org/10.7717/peerj.3553

37. Maurer F, Müller S, Bauer P (2011) Suppression of Fe deficiency gene expression by jasmonate. Plant Physiol Biochem 49:530-536. https://doi.org/10.1016/j.plaphy.2011.01.025

38. Paz RC, Rocco RA, Reinoso H et al (2012) Comparative study of alkaline, saline, and mixed salinealkaline stresses with regard to their effects on growth, nutrient accumulation, and root morphology of Lotus tenuis. J Plant Growth Regul 31:448-459. https://doi.org/10.1007/s00344-011-9254-4

39. Pérez-Martín L, Busoms S, Tolrà R et al (2021) Transcriptomics reveals fast changes in salycilate and jasmonate signaling pathways in shoots of carbonate-tolerant Arabidopsis thaliana under bicarbonate exposure. Int J Mol Sci 22:1226. https://doi.org/10.3390/ijms22031226

40. Porta J (1986) Técnicas y Experimentos en Edafologia, 282 pp. Coll. Oficial d'Eng. Agron. de Catalunya, Barcelona, Spain

41. Pons X (2004) MiraMon. Sistema d'Informació Geogràfica i software de Teledetecció. Centre de Recerca Ecològica i Aplicacions Forestals, CREAF. Bellaterra. ISBN: 84-931323-4-9

42. Poschenrieder C, Fernández JA, Rubio L et al (2018) Transport and use of bicarbonate in plants: current knowledge and challenges ahead. Int J Molec Sci 19:1352. https://doi.org/10.3390/ijms19051352

43. Riaz MU, Ayub MA, Khalid $\mathrm{H}$ et al (2020) Fate of micronutrients in alkaline soils. pp 577-613 In Resources Use Efficiency in Agriculture. S. Kumar, RS Meena \& MK Jharia Eds. Springer, Singapore. ISBN 978-981-15-6952-4

44. Rolly NK, Imran QM, Lee IJ et al (2020) Salinity stress-mediated suppression of expression of salt overly sensitive signaling pathway genes suggests negative regulation by AtbZIP62 transcription factor in Arabidopsis thaliana. Int J Molec Sci 21:1726. https://doi.org/10.3390/ijms21051726

45. Rubio F, Nieves-Cordones M, Horie T, Sahabala S (2020) Doing "business as usual" comes with a cost: evaluating energy cost of maintaining plant intracellular $\mathrm{K}$. homeostasis under saline conditions New Phytol 225:1097-1104. https://doi.org/10.1111/nph.15852

46. Sandhu D, Cornacchione MV, Ferreira JF, Suarez DL (2017) Variable salinity responses of 12 alfalfa genotypes and comparative expression analyses of salt-response genes. Sci Rep 7:1-18. https://www.nature.com/articles/srep42958

47. Saslis-Lagoudatis CH, Hua X, Bui E (2015) Predicting species' tolerance to salinity and alkalinity using distribution data and geochemical modelling: a case study using Australian grasses. Ann Bot 343-351. https://doi.org/10.1093/aob/mcu248

48. Satbhai SB, Setzer C, Freynschlag F et al (2017) Natural allelic variation of FRO2 modulates Arabidopsis root growth under iron deficiency. Nature Commun 8:15603. 
https://www.nature.com/articles/ncomms15603

49. Scheiner SM (2013) The genetics of phenotypic plasticity. XII. Temporal and spatial heterogeneity. Ecol Evolution 3:4596-4609. https://doi.org/10.1002/ece3.792

50. Schneider CA, Rasband WS, Eliceiri KW (2012) NIH Image to ImageJ: 25 years of image analysis. Nat Methods 9:671-675. https://www.nature.com/articles/nmeth.2089

51. Scholl RL, May ST, Ware DH (2000) Seed and molecular resources for Arabidopsis. Plant Physiol 124:1477-1480. https://doi.org/10.1104/pp.124.4.1477

52. Schöttler MA, Tóth SZ, Boulouis A, Kahlau S (2015) Photosynthetic complex stoichiometry dynamics in higher plants: biogenesis, function, and turnover of ATP synthase and the cytochrome $b_{6} f$ complex. J Exp Bot 66:2373-2400. https://doi.org/10.1093/jxb/eru495

53. Shi D, Sheng $Y$ (2005) Effect of various salt-alkaline mixed stress conditions on sunflower seedlings and analysis of their stress factors. Environ Exp Bot 54:8-21. https://doi.org/10.1007/s11099-0110037-8

54. Shi H, Ishitani M, Kim C, Zhu JK (2000) The Arabidopsis thaliana salt tolerance gene SOS1 encodes a putative $\mathrm{Na}^{+} / \mathrm{H}^{+}$antiporter PNAS. 97:6896-6901. https://dx.doi.org/10.1073\%2Fpnas.120170197

55. Singh A (2021) Soil salinization management for sustainable development: A review. J Environ Manag 277:111383. https://doi.org/10.1016/j.jenvman.2020.111383

56. Soltanpour PN, Schwab AP (1977) A new soil test for simultaneous extraction of macro and micronutrients in alkaline soils. Commun Soil Sci Plant Anal 8:195-207. https://doi.org/10.1080/00103627709366714

57. Sonmez S, Buyuktas D, Okturen F, Cirak S (2008) Assessment of different soil to water ratios (1:1, $1: 2.5,1: 5)$ in soil salinity studies. Geoderma 144:361-369. https://doi.org/10.1016/j.geoderma.2007.12.005

58. Terés J, Busoms S, Pérez-Martín L et al (2019) Soil carbonate drives local adaptation in Arabidopsis thaliana. Plant Cell Environ 42:2384-2398. https://doi.org/10.1111/pce.13567

59. Terry N, Zayed AM (1995) Physiology and biochemistry of leaves under iron deficiency. pp 283-294 In Iron nutrition in Soils and Plants J. Abadía Ed. Kluwer Academic Publ, Dordrecht ISBN 0-7923-2900-7

60. Valladares F, Matesanz S, Guilhaumon F et al (2014) The effects of phenotypic plasticity and local adaptation on forecast of species range shifts under climate change. Ecol Lett 17:1351-1364. https://doi.org/10.1111/ele.12348

61. Wang H, Takano T, Liu S (2018) Screening and evaluation of saline alkaline tolerant germplasm of rice (Oryza sativa L.) in soda saline alkali soil. Agronomy 8:1-16. https://doi.org/10.3390/agronomy8100205

62. Waters BM, Amundsen K, Graef G (2018) Gene expression profiling of iron deficiency chlorosis sensitive and tolerant soybean indicates key roles for phenylpropanoids under alkalinity stress. Front. Plant Sci 9:10. https://doi.org/10.3389/fpls.2018.00010 
63. Zhang H, Li X, Nan X et al (2017a) Alkalinity and salinity tolerance during seed germination and early seedling stages of three alfalfa (Medicago sativa L) cultivars. Leg Res 40:853. http://10.0.73.117/Ir.v0i0.8401

64. Zhang H, Liu X, Zhang $\mathrm{H}$ et al (2017b) Root damage under alkaline stress is associated with reactive oxygen species accumulation in rice (Oryza sativa L.). Front Plant Sci 8:1580. https://doi.org/10.3389/fpls.2017.01580

65. Yang C, Chong J, Li C et al (2007) Osmotic adjustment and ion balance traits of an alkali resistant halophyte Kochia sieversiana during adaptation to salt and alkali conditions. Plant Soil 294:263276. https://link.springer.com/article/ 10.1007/s11104-007-9251-3

66. Ye J, Coulouris G, Zaretskaya I, Cutcutache I, Rozen S, Madden TL (2012) Primer-BLAST: a tool to design target-specific primers for polymerase chain reaction. BMC Bioinformatics 13:134. http://www.biomedcentral.com/1471-2105/13/134

\section{Figures}

\section{Figure 1}

Arabidopsis thaliana distribution and soil characteristics. (A) Geographic location of the Catalan Arabidopsis demes (black stars) and the two soil sampling points (purple circles) in the saline-alkaline soil map of Europe. (B) Carbonate $\left(\mathrm{CaCO}_{3}\right)$ vs $\mathrm{Na}^{+}$content, (C) PCA of soil parameters, and (D) normalized difference of 14 elements in the native soils of 19 A. thaliana demes. (E) Neighbour-joining cladograms of the whole-genome (37,574 SNP sites) among 74 Arabidopsis individuals from our study region and the reference Col-0. A. thaliana demes are classified in three groups according to its native soil characteristics in G1-plants (low $\mathrm{Na}^{+}$and high $\mathrm{CaCO}_{3}$, blue), G2-plants (intermediate levels of $\mathrm{Na}$ and $\mathrm{CaCO}_{3}$, green), and $\mathrm{G} 3$-plants (high $\mathrm{Na}$ and low $\mathrm{CaCO}_{3}$, red). 
(A)

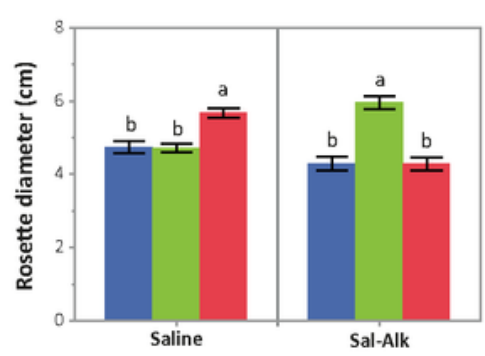

(B)

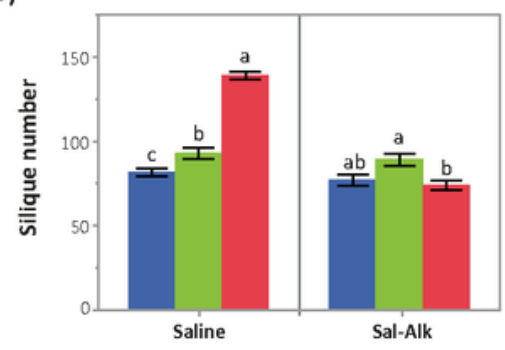

(D)

Saline

n* S
(C)

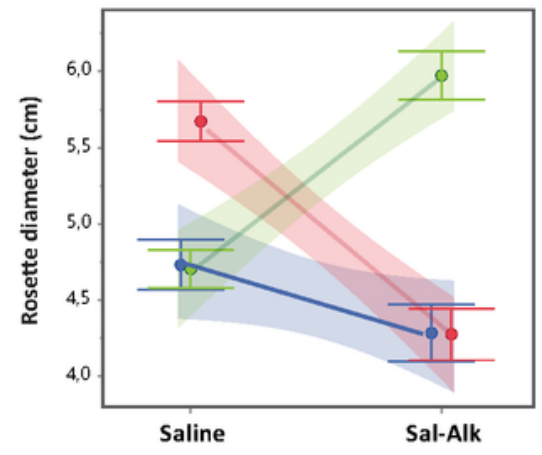

(E)

Sal-Alk

S*

Figure 2

Soil reciprocal transplant performance of $\boldsymbol{A}$. thaliana groups. Mean $\pm \mathrm{SE}$ of $(\mathrm{A})$ growth (rosette diameter, $\mathrm{RD}$ ) and (B) fitness (number of siliques produced) of $A$. thaliana plants cultivated in saline (BLA site) and saline-alkaline (ESC site) soil in semi-controlled conditions (UAB greenhouse). Letters indicate significant differences (Tukey's HSD, $\mathrm{P}<0.05$ ) between $A$. thaliana demes groups (G1=blue, G2=green, G3=red). (C) Mean growth $\pm 95 \%$ confidence intervals of G1, G2 and G3 plants cultivated in saline and saline-alkaline 
soil in a greenhouse. Normalized difference of 12 elements in the leaves of plants from the three groups cultivated in (D) saline soil or (E) saline-alkaline soil in a greenhouse. Elements exhibiting significant differences (according to a t-test) are marked with an asterisk $\left({ }^{*}, \mathrm{P}<0.05\right)$.

(A)

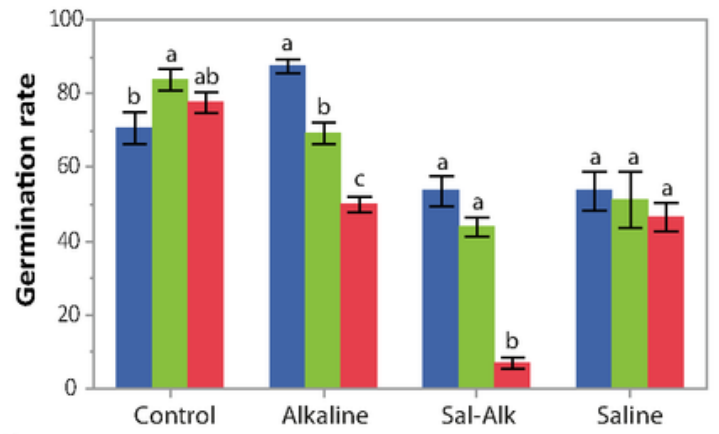

(B)

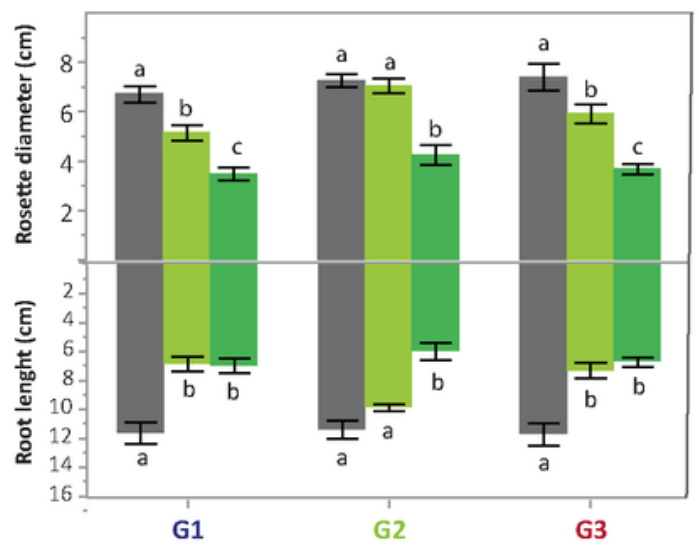

Figure 3 
Salinity-alkalinity tolerance of $\boldsymbol{A}$. thaliana groups. (A) Germination rate (\%) \pm SE of Arabidopsis seeds sown in $\mathrm{MS}$ plates with no $\mathrm{NaCl}$ or $\mathrm{NaHCO}_{3}$ (Control treatment, $\mathrm{pH} 5.9$ ), with $50 \mathrm{mM}$ of $\mathrm{NaCl}$ (Saline treatment, pH 5.9), with $10 \mathrm{mM} \mathrm{NaHCO}_{3}$, (Alkaline treatment, pH 8.3), or with $40 \mathrm{mM} \mathrm{NaCl}+10 \mathrm{mM}$ $\mathrm{NaHCO}_{3}$ (Sal-Alk treatment, $\mathrm{pH}$ 8.3). Letters indicate significant differences (Tukey's HSD, $\mathrm{P}<0.05$ ) between $A$. thaliana demes groups (G1=blue, $\mathrm{G} 2=$ green, $\mathrm{G} 3=$ red). (B) Mean $\pm \mathrm{SE}$ of rosette diameter (cm) and root length $(\mathrm{cm})$ of $A$. thaliana plants cultivated in hydroponics under Control $(0 \mathrm{mM} \mathrm{NaCl}+0 \mathrm{mM}$ $\mathrm{NaHCO}_{3}, \mathrm{pH} 5.9$, grey), Sal-Alk-1 treatment (40 mM NaCl + $10 \mathrm{mM} \mathrm{NaHCO}_{3}, \mathrm{pH} 8.3$, light green), and SalAlk-2 treatment $\left(60 \mathrm{mM} \mathrm{NaCl}+15 \mathrm{mM} \mathrm{NaHCO}_{3}\right.$, $\mathrm{pH}$ 8.3, dark green) for 15 days. Letters indicate significant differences (Tukey's HSD, $\mathrm{P}<0.05$ ) between treatments for each $A$. thaliana deme group.

\section{Figure 4}

Potential effects of saline-alkaline candidate genes. (A) Relative rosette diameter, root length and biomass ( $X_{\text {Treatment }} / X_{\text {Control }}$ ) of G1-plants (blue), G2-plants (green), G3-plants (red), and Col-0 plants (purple) cultivated in 2:1 sand:perlite substrate irrigated with no $\mathrm{NaCl}$ or $\mathrm{NaHCO}_{3}$ (Control, pH 5.9), with 50 $\mathrm{mM}$ of $\mathrm{NaCl}$ (Saline, pH 5.9), with $10 \mathrm{mM} \mathrm{NaHCO}_{3}$, (Alkaline, pH 8.3), or with $40 \mathrm{mM} \mathrm{NaCl}+10 \mathrm{mM}$ $\mathrm{NaHCO}_{3}$ (Sal-Alk treatment, $\mathrm{pH}$ 8.3) for 15 days. Letters indicate significant differences (Tukey's HSD, $\mathrm{P}<$ 0.05) between $A$. thaliana groups. Neighbour-joining cladograms of (B) SOS1 allele (based on 28 SNPs), (D) FRO2 allele (based on 37 SNPs), (F) CCB4 allele (based on 134 SNPs), and (H) NINJA allele (based on 25 SNPs). Each individual is colored according to the $A$. thaliana demes groups (G1=blue, G2=green, G3 $=$ red, REF = purple). Relative transcript expression (treatment vs control) of (C) SOS1, (E) FRO2 (G) CCB4, and (I) NINJA in shoots of triplicate biological replicates of plants expose to Saline (red bars), Alkaline (blue bars), or Sal-Alk (green bars) treatments for 15 days. Data represent the mean \pm SE of three plants per accession. Letters indicate significant differences (Tukey's HSD, $\mathrm{P}<0.05$ ) between treatments.

\section{Supplementary Files}

This is a list of supplementary files associated with this preprint. Click to download.

- SupplementaryFigures.pdf

- SupplementaryDatasets.xlsx 